\title{
Characterizing Fenbuconazole and Propiconazole Sensitivity and Prevalence of 'Mona' in Isolates of Monilinia fructicola from New York
}

Sara M. Villani and Kerik D. Cox, Department of Plant Pathology and Plant-Microbe Biology, New York State Agricultural Experiment Station, Cornell University, Geneva, NY 14456

\begin{abstract}
Villani, S. M., and Cox, K. D. 2011. Characterizing fenbuconazole and propiconazole sensitivity and prevalence of 'Mona' in isolates of Monilinia fructicola from New York. Plant Dis. 95:828-834.

Demethylation inhibitor (DMI) resistant populations of Monilinia fructicola, the causal agent of brown rot of stone fruit, and the presence of the genetic DMI resistance determinant 'Mona' have been reported throughout the eastern United States. In this study, we endeavored to conduct a comprehensive investigation of DMI sensitivity, the prevalence of 'Mona', and implications of DMI use for M. fructicola populations from New York and Pennsylvania. Of the 18 orchards surveyed, only 9 were primarily composed of isolates with either resistance or reduced sensitivity to fenbuconazole and propiconazole. The DMI resistance determinant 'Mona' was only found in 5 orchards,

ways present in resistant isolates. These results suggested that 'Mona' only contributes to a portion of the quantitative resistance response to DMI fungicides. On detached blossoms and fruit, protective applications of fenbuconazole (Indar 2F) against isolates with resistance or reduced sensitivity resulted in significantly $(P<0.05)$ lower brown rot incidence compared to applications of propiconazole (Orbit 3.6EC) and water controls. By comparison, therapeutic applications of fenbuconazole and propiconazole against isolates with resistance or reduced sensitivity provided little to no reduction in brown rot incidence on blossoms and fruit.
\end{abstract} present in isolates with a range of sensitivity phenotypes, and not al-
Monilinia fructicola (G. Winter) Honey and Monilinia laxa (Aderh. \& Ruhland) Honey are the two species of Monilinia responsible for causing brown fruit rot of stone fruit in the United States $(7,17,22,30,32)$. While both species are reported to cause blossom blight and brown fruit rot in stone fruit production regions throughout the country $(17,22,30), M$. fructicola is the species of foremost concern to stone fruit producers in the eastern United States $(3,23,26)$. The use of site-specific fungicides including benzimidazoles (1970s), sterol demethylation inhibitors (DMIs, 1980s), and more recently quinone outside inhibitors (QoIs, mid-1990s) in disease management programs has enhanced our ability to manage a broad spectrum of phytopathogenic fungi, including Monilinia spp., while minimizing effects to nontarget organisms $(10,11$, 26,32,35). Against $M$. fructicola, these fungicide classes provide a high level of activity $(14,21,32)$ both as protectant and as a therapeutic agent $(8,11)$. However, repetitive use of these chemistries may select for the emergence of fungicide-resistant populations $(8,26,27,34)$. Such was the case for the benzimidazoles, and resistant field populations of $M$. fructicola developed in the early 1980s $(10,28,35)$.

Since the emergence of benzimidazole resistance more than 20 years ago, DMI fungicides have become the industry standard for controlling brown rot of stone fruit in the United States $(2,26,27,34)$. Unfortunately, DMI resistance has recently been reported in $M$. fructicola populations from Georgia, South Carolina, New Jersey, West Virginia, and New York $(1,9,15,23,26)$. Additionally, the presence of 'Mona', a 65-bp insert upstream of the CYP51Al gene, was shown to be correlated with resistance to propiconazole in field populations of M. fructicola $(15,16)$. While assaying isolates for the presence of 'Mona' allows for a quick molecular evaluation of resistance, relationships between the presence or absence of 'Mona' and in vitro sensitivity to propiconazole

Corresponding author: K. D. Cox, E-mail: kdc33@ cornell.edu

Accepted for publication 2 March 2011.

doi:10.1094/PDIS-12-10-0943

(C) 2011 The American Phytopathological Society and other DMI fungicide chemistries such as fenbuconazole in a larger collection of $M$. fructicola isolates $(>100)$ is largely unknown. Moreover, the prevalence of isolates containing 'Mona' within an orchard population and practical implications of the presence of 'Mona' on the development of disease have also yet to be studied in detail.

From 2005 to 2009, stone fruit operations in New York and Pennsylvania reported diminished efficacy or control failure (preharvest brown fruit rot incidence exceeding 5\%) following application of fenbuconazole or propiconazole DMI fungicide products. The discovery of 'Mona' in New York (15) in conjunction with reports of brown fruit rot outbreaks in well managed orchards in 2005 prompted us to conduct a survey of $M$. fructicola populations. The goals of our study were to: (i) determine the sensitivity and the prevalence of 'Mona' in $M$. fructicola populations from orchards with brown rot outbreaks following applications of DMI fungicides; (ii) examine the relationship between 'Mona' and in vitro sensitivity to two commonly used DMI fungicides, fenbuconazole and propiconazole; and (iii) evaluate the efficacy of fenbuconazole (Indar 2F) and propiconazole (Orbit 3.6EC) on detached cherry blossoms and mature cherry fruit inoculated with $M$. fructicola isolates belonging to one of three DMI-sensitivity phenotypes.

\section{Materials and Methods}

In vitro sensitivity of $M$. fructicola populations to the DMI fungicides fenbuconazole and propiconazole. From 2005 to 2009, 30 baseline (orchard TLR) and $385 \mathrm{M}$. fructicola isolates putatively resistant to DMI fungicides were collected from 17 stone fruit orchards in New York and one in Pennsylvania (Table 1). Stone fruit hosts included sweet (Prunus avium) and tart cherry (P. cerasus), plum $(P$. domestica), and peach and nectarine $(P$. persica) with $221,85,11,77$, and 21 isolates collected from each of the stone fruit hosts, respectively. To ensure collections were representative of an entire orchard or block, no more than three fruit were collected from any one tree, and collections were made uniformly from affected trees (more than $25 \mathrm{~m}$ away from one another) throughout the entire block or orchard. With the exception of the baseline population, which had never been exposed to any DMI fungicides, all other orchards surveyed were commercial operations with a history of no fewer than 15 DMI applications since 
orchard establishment. All collected fruit were stored separately in paper bags at $4^{\circ} \mathrm{C}$ prior to conidial isolation to reduce the risk of cross-contamination between isolates.

Isolation of $M$. fructicola conidia was accomplished by gently scraping brown rot spores from the surface of mature stone fruit, using an autoclaved sterile toothpick, into $1 \mathrm{ml}$ of sterile distilled water. Conidial suspensions were vortexed for $30 \mathrm{~s}$ at 2,500 rpm using a variable speed vortex mixer (Vortex Genie 2, Scientific Industries), and $100 \mu \mathrm{l}$ of the suspension was distributed onto $1.5 \%$ water agar amended with $50 \mu \mathrm{g} / \mathrm{ml}$ streptomycin sulfate (Sigma Aldrich). Following $24 \mathrm{~h}$ of incubation at $24^{\circ} \mathrm{C}$, four germinating conidia from each isolate were transferred from the water agar plate and placed on potato dextrose agar (PDA) (Difco Laboratories) amended with $50 \mu \mathrm{g} / \mathrm{ml}$ streptomycin sulfate. After 5 days of incubation at $24^{\circ} \mathrm{C}$, a single monoconidial colony from each isolate was selected for in vitro fungicide efficacy testing. For each isolate, two agar plugs ( $5 \mathrm{~mm}$ diameter) were removed from the growing margin of the colony and maintained ( $<5$ days) on PDA at $24^{\circ} \mathrm{C}$ prior to in vitro sensitivity testing. Following isolation, all isolates were confirmed to be $M$. fructicola as previously described (3). However, confirmation of species identity for isolates collected from orchard locations between 2005 and 2007 was performed in 2008 after the confirmation of M. laxa in New York (3).

$M$. fructicola isolates were subjected to in vitro mycelial relative growth assays $(2,15)$ to determine sensitivity to the DMI fungicides fenbuconazole and propiconazole. Sensitivity to each fungicide was evaluated at discriminatory concentrations representing $100 \times$ the historical baseline $\mathrm{EC}_{50}$ values for New York State established in 1992 (31). Discriminatory media of $0.3 \mu \mathrm{g} / \mathrm{ml}$ fenbuconazole and $0.9 \mu \mathrm{g} / \mathrm{ml}$ propiconazole were achieved by amending PDA with a working solution of the respective analytical grade fungicide standard (PESTANAL, Sigma-Aldrich) dissolved in acetone. Mycelial relative growth assays were conducted as previously described $(2,15)$. Relative growth assays for individual orchard locations were conducted within 2 weeks of isolate collection to avoid potential DMI instability (2). With the exception of the two 2005 collections, isolates NYC4B and NYC6B (15), maintained on 0.03 $\mu \mathrm{g} / \mathrm{ml}$ fenbuconazole, and TLR-4 and TLR-10 (this study) were included as DMI-R and DMI-S positive controls in all sensitivity assays, respectively. In 2005, the first year of the survey, DMI-R isolates had not been discovered in New York. Relative growth for each isolate was determined as the mean diameter of two colonies from each of three replicate agar plates, and from these data, a mean percent relative growth $(\% \mathrm{RG})$ was determined for both the isolate and the entire collection of all isolates from a specific orchard location using the PROC MEANS procedure of SAS (version 9.2; SAS Institute). Population normality with respect to $\%$ RG responses was also determined for each orchard site using the PROC UNIVARIATE procedure of SAS. Individual isolates were subsequently classified into three distinct categories of DMI sensitivity on the basis of \% RG in a manner similar to those used to classify $M$. fructicola sensitivity to benzimidazole and DMI fungicides $(2,15,18)$. Specifically, isolates were classified as sensitive to a DMI fungicide (DMI-S) if relative growth values did not exceed $10 \%$, were classified as reduced sensitive (DMI-RS) if relative growth was greater than $10 \%$ but did not exceed $30 \%$, or were classified as resistant (DMI-R) if relative growth exceeded $30 \%$ on PDA amended at the discriminatory concentration for a given fungicide.

Extraction of genomic DNA and upstream amplification of CYP51A1 for the detection of 'Mona'. Genomic DNA was extracted from the mycelium of each monoconidial $M$. fructicola isolate using a mycelium boiling technique previously described and validated $(15,17)$. To determine the presence of 'Mona', amplification of a region upstream of the CYP51A1 gene was performed by polymerase chain reaction (PCR) using the primer pair INS65- $F$ and INS65- $R$ as previously described (15) and the GoTaq Flexi DNA Polymerase kit (Promega Corporation) with an iCycler thermal cycler (Bio-Rad Laboratories). PCR products were separated on a $2.0 \%$ agarose gel in $1 \times$ TAE buffer $(44.5 \mathrm{mM}$ Tris-borate, $1 \mathrm{mM}$ EDTA, $\mathrm{pH}$ 8.0) for $1 \mathrm{~h}$. Photographs of the gel were taken on a KODAK Gel Logic 200 Imaging System (Eastman Kodak Company, Rochester, NY). Restriction fragment length polymorphism (RFLP) analysis of PCR fragments amplified with primers INS65-F and INS65-R was conducted as previously described on all M. fructicola isolates (15).

Evaluation of DMI fungicides for control of brown rot on detached blossoms and fruit. A series of experiments were conducted to evaluate the effectiveness of the DMI fungicides fenbuconazole and propiconazole against DMI-sensitive (DMI-S), DMI-

Table 1. In vitro sensitivity of Monilinia fructicola populations to the demethylation inhibitor (DMI) fungicides fenbuconazole and propiconazole collected from 18 stone fruit orchards between 2005 and 2009

\begin{tabular}{|c|c|c|c|c|c|c|c|c|c|}
\hline Year & County & $\begin{array}{l}\text { Orchard } \\
\text { designation }\end{array}$ & $\begin{array}{l}\text { Host common } \\
\text { name }\end{array}$ & $\begin{array}{c}\text { Total } \\
\text { isolates }\end{array}$ & $\begin{array}{l}\text { 'Mona' } \\
\text { isolates }\end{array}$ & $\begin{array}{c}\text { Mean } \% \text { relative } \\
\text { growth } \\
\text { on } 0.3 \mu \mathrm{g} / \mathrm{ml} \\
\text { fenbuconazole }\end{array}$ & $\begin{array}{l}\text { Fenbuconazole } \\
\text { DMI-S, RS, R } \\
\text { isolates }\end{array}$ & $\begin{array}{c}\text { Mean } \% \text { relative } \\
\text { growth } \\
\text { on } 0.9 \mu \mathrm{g} / \mathrm{ml} \\
\text { propiconazole }\end{array}$ & $\begin{array}{c}\text { Propiconazole } \\
\text { DMI-S, RS, R } \\
\quad \text { isolates }\end{array}$ \\
\hline 2005 & Niagara & Bittner05 & Peach & 37 & 0 & $2.4 \pm 0.9$ & $33,4,0$ & $1.5 \pm 0.6$ & $36,1,0$ \\
\hline 2005 & Columbia & HVL05 & Tart cherry & 6 & 0 & $0.0 \pm 0.0$ & $6,0,0$ & $0.0 \pm 0.0$ & $6,0,0$ \\
\hline 2006 & Ontario & RJ06 & Sweet cherry & 30 & 16 & $26.8 \pm 2.8$ & $2,14,14$ & $15.6 \pm 2.7$ & $7,9,14$ \\
\hline 2006 & Ontario & TLR & Sweet cherry & 30 & 0 & $0.9 \pm 0.6$ & $30,0,0$ & $0.1 \pm 0.1$ & $30,0,0$ \\
\hline 2007 & Columbia & HVC07 & Tart cherry & 41 & 0 & $12.1 \pm 1.5$ & $21,19,1$ & $6.8 \pm 1.1$ & $28,12,1$ \\
\hline 2007 & Niagara & EO-07 & Plum & 11 & 0 & $25.8 \pm 1.9$ & $0,8,3$ & $12.2 \pm 1.1$ & $2,6,3$ \\
\hline 2007 & Suffolk & LIWicomb & Peach & 3 & 0 & $8.0 \pm 0.2$ & $3,0,0$ & $0.0 \pm 0.0$ & $3,0,0$ \\
\hline 2007 & Wayne & B. Palmer & Tart cherry & 27 & 3 & $10.2 \pm 3.2$ & $21,3,3$ & $3.0 \pm 1.1$ & $24,3,0$ \\
\hline 2007 & Monroe & МСТY & Peach & 3 & 0 & $19.5 \pm 1.5$ & $0,3,0$ & $16.6 \pm 4.8$ & $1,2,0$ \\
\hline 2007 & Ontario & NYSAES & Peach & 3 & 0 & $4.9 \pm 2.6$ & $3,0,0$ & $0.0 \pm 0.0$ & $3,0,0$ \\
\hline 2008 & Niagara & DB08 & Tart cherry & 3 & 0 & $6.0 \pm 3.0$ & $3,0,0$ & $3.6 \pm 3.6$ & $2,1,0$ \\
\hline 2008 & Niagara & New Royal & Sweet cherry & 25 & 0 & $21.2 \pm 1.4$ & $2,22,1$ & $15.1 \pm 1.2$ & $2,20,3$ \\
\hline 2008 & Niagara & Bittner108 & Sweet cherry & 85 & 0 & $18.3 \pm 0.9$ & $10,66,9$ & $13.6 \pm 0.9$ & $34,48,3$ \\
\hline 2008 & Niagara & Bittner208 & Tart cherry & 8 & 0 & $17.9 \pm 2.7$ & $1,6,1$ & $13.4 \pm 1.8$ & $3,5,0$ \\
\hline 2008 & Ontario & JFNec08 & Nectarine & 21 & 3 & $8.6 \pm 3.4$ & $16,2,3$ & $4.3 \pm 2.1$ & $17,3,1$ \\
\hline 2008 & Wayne & Beckens FF & Sweet cherry & 9 & 9 & $39.2 \pm 5.0$ & $0,1,8$ & $25.7 \pm 2.3$ & $1,7,1$ \\
\hline 2009 & Lancaster ${ }^{\mathrm{c}}$ & ChocMF & Peach & 31 & 31 & $77.2 \pm 3.5$ & $0,0,31$ & $39.4 \pm 2.0$ & $0,7,24$ \\
\hline 2009 & Ontario & JFCh09 & Sweet cherry & 42 & 0 & $0.3 \pm 0.2$ & $42,0,0$ & $0.0 \pm 0.0$ & $42,0,0$ \\
\hline
\end{tabular}

${ }^{a}$ Sensitivity was expressed as percent colony growth on medium amended with analytical grade fungicides relative to that on nonamended medium. Values are means and standard errors of all isolates within the population with measurements made from two colonies for each isolate from two independent replicate plating events.

${ }^{\mathrm{b}}$ Data refer to number of isolates classified as DMI-S (sensitive, growth values below 10\%), DMI-RS (reduced sensitive, growth value between 10 and $30 \%$ ), and DMI-R (resistant, growth value above 30\%) phenotypes, respectively.

c This orchard site was in Lancaster County, PA. 
reduced sensitive (DMI-RS), and DMI-resistant (DMI-R) isolates of $M$. fructicola. A total of four independent experiments were conducted on both detached blossoms and fruit, and using both protective and therapeutic application timings: (i) protective application timing on detached blossoms; (ii) protective application timing on detached fruit; (iii) therapeutic application timing on detached blossoms; and (iv) therapeutic application timing on detached fruit.

In each of the four experiments, two DMI fungicides, fenbuconazole (Indar 2F, Dow AgroSciences LLC) and propiconazole (Orbit 3.6EC, Syngenta), were applied to detached cherry blossoms or fruit inoculated with one of three M. fructicola isolates: TLRR-6, HV07-4.1.4, and B. Palmer-8.1 representing DMI-S, DMI-RS, and DMI-R phenotypes, respectively. Isolates were chosen to represent the upper range in \% RG of each sensitivity class, and in turn the greatest challenge to fungicide efficacy for each phenotype. Fruit and blossoms were collected from P. cerasus 'Montmorency' tart cherry trees planted at the Crittenden North Farm at the New York State Agricultural Experiment Station in Geneva. For each treatment combination (e.g., fungicide $\times$ isolate), either 33 blossoms ( $<2$ days after fully opening) were placed in $1.5-\mathrm{ml}$ microcentrifuge tubes filled with sterile distilled water, or 25 fruit (harvest maturity and less than one day postharvest) were placed in a 50 plug TLC Pro Tray Insert (International Greenhouse Company) split in half so that it contained 25 divisions to isolate fruit from one another. Fruit were also gently hand cleaned with Kimwipes EX-L (Kimberley-Clark) moistened with $70 \%$ ethanol to partially sanitize surfaces prior to treatment or inoculation. Individual blossoms and fruit were considered experimental units in the measure of disease incidence, and the number of fruit was chosen based on considerations of a similar study (8), but with an increased number (i.e., six to eight times more fruit) to allow for a higher degree of resolution with disease incidence values. Each of the fungicide by isolate treatment combinations was replicated three times within each experiment.

Applications of fenbuconazole and propiconazole were applied at $157 \mu \mathrm{l} /$ liter and $104 \mu \mathrm{l} /$ liter, respectively, to runoff (i.e., droplets were visible on blossoms and fruit) using an airbrush sprayer (Aztek 320A, Testor). Fungicide rates represented the current labeled rate for preharvest brown rot control of cherries. In addition to the fungicide applications, an application of sterile deionized water was also made to serve as a control treatment. In the experiments investigating protective applications of fungicides on blossoms and fruit, fungicide applications were made $24 \mathrm{~h}$ prior to inoculation. By contrast, fungicide applications were made $48 \mathrm{~h}$ after inoculation with the $M$. fructicola isolates in experiments investigating therapeutic activity on blossoms and fruit. Inoculation was accomplished by applying $10^{4} \mathrm{M}$. fructicola spores $/ \mathrm{ml}$ to blossoms or fruit with the airbrush sprayer until runoff as described above for fungicide applications. For all airbrush applications, different nozzles and glass solution jars were used for fungicides and pathogens. Additionally, the airbrush was flushed three times with $25 \mathrm{ml}$ of fresh sterile distilled water between fungicide applications and M. fructicola inoculations. Noninoculated fruit and blossoms treated with sterile distilled water were also included as additional checks for confounding background infections. Treated or inoculated blossoms and fruit in their microcentrifuge tubes or trays were placed in transparent plastic containers containing four paper towel sheets saturated with water and sealed with clear packing tape to maintain near $100 \%$ relative humidity. After 5 days of incubation at $24^{\circ} \mathrm{C}$ following inoculation, disease incidence was evaluated as the percentage of blighted sporulating hypanthia, or the percentage of sporulating fruit for each of three treatment replications. Each of the experiments was independently repeated for a total of three times during the course of the study. To ensure that each of the isolates' DMI sensitivity phenotypes were maintained during the course of experimentation, spores were removed from infected cherries or blossoms at the end of each experiment and subject to in vitro sensitivity testing as described above.
Disease incidence data for the protective and therapeutic application timing experiments were analyzed separately for blossom blight and brown fruit rot. Data were analyzed by analysis of variance (ANOVA) for a factorial design with isolate phenotype and fungicide treatment as the two treatment factors. Analysis was performed using the mixed models procedure (Proc MIXED) of SAS. Main effects and interactions were considered statistically significant at $\alpha=0.05$. Adjusted estimated mean disease incidences are reported for specific isolate by fungicide treatment combinations using the LSMEANS procedure of SAS. All percent data were subject to arcsine square root transformation prior to analysis to stabilize the variances.

\section{Results}

Sensitivity of $M$. fructicola populations to the DMI fungicides fenbuconazole and propiconazole. Of the 18 orchards surveyed from 2005 to 2009,10 had a sufficiently large planting (>10 ha) and sufficient brown fruit rot incidence $(>15 \%)$ to allow collections of $>20$ isolates under our sampling scheme (i.e., $>7$ trees with brown fruit rot more than $25 \mathrm{~m}$ away from one another). The remaining 8 orchards were either from small, diversified farm operations with small plantings $(<1.25 \mathrm{ha})$ and/or had fewer trees with brown fruit rot, reducing our collection to $<15$ isolates under our sampling scheme.

At discriminatory doses of $100 \times$ the historical baseline $\mathrm{EC}_{50}$, population means for commercial orchard sites had consistently lower mean percent relative growth $(\% \mathrm{RG})$ values for propiconazole compared to fenbuconazole (Table 1). Similarly, the baseline orchard location TLR also had slight differences in RG between the two fungicides for all 30 isolates (data not shown). However, all TLR isolates still demonstrated an expected high level of sensitivity to both fenbuconazole $(0.3 \mu \mathrm{g} / \mathrm{ml})$ and propiconazole $(0.9$ $\mu \mathrm{g} / \mathrm{ml}$ ) with $\%$ RG ranging from 0.0 to $7.0 \%$ (mean $1.02 \pm 0.4 \%$ ) and 0.0 to $2.0 \%$ (mean $0.10 \pm 0.1 \%$ ), respectively. Despite a history of exposure to DMI fungicides, isolates from commercial orchards HVL05 and JFCh09 also had a level of fenbuconazole and propiconazole sensitivity (mean $\% \mathrm{RG}<1.0$ ) similar to that of the baseline population (Table 1). Although not baseline sensitive, orchards HVC07, B. Palmer, and JFNec08 were composed primarily of DMI-S isolates (mean \%RG $<10 \%$ ). While orchards MCTY, Bittner108, and Bittner208 had some sensitive isolates, the majority had DMI-RS (mean \%RG between 10 and 30\%) phenotypes. By comparison, orchards RJ06, EO-07, New Royal, Beckens FF, and ChocMF were composed primarily of isolates with DMI-RS or DMI-R phenotypes (mean \%RG > 30\%) (Table 1).

The prevalence of 'Mona' and in vitro sensitivity to the DMI fungicides fenbuconazole and propiconazole. Upstream amplification of the CYP51A1 gene for the detection of the DMI resistant determinant 'Mona' yielded a 311-bp fragment lacking the 'Mona' determinant from $342(82 \%)$ of the 415 M. fructicola isolates. With the exception of 11 isolates from orchard RJ06 that produced a unique 1,815-bp fragment, a 376-bp fragment containing the 65-bp 'Mona' insert was amplified in the remaining 62 $(15 \%)$ isolates from five commercial orchards. At two orchards, Beckens FF and ChocMF, all of the isolates tested positive for the 'Mona' insert (Table 1). With the exception of orchards surveyed in 2005, isolates with the 'Mona' insert were present in at least one commercial orchard during every year of our investigation.

On media amended with $0.3 \mu \mathrm{g} / \mathrm{ml}$ fenbuconazole and 0.9 $\mu \mathrm{g} / \mathrm{ml}$ propiconazole, isolates with the 'Mona' genotype had $\%$ RG values ranging from 22.8 to $137.6 \%$ (mean $\%$ RG of $60.8 \pm$ $3.1 \%$ ) and 13.0 to $68.5 \%$ (mean $\% \mathrm{RG}$ of $32.9 \pm 1.5 \%$ ), respectively. The majority (59 of 62) of isolates with the 'Mona' genotype were classified as DMI-R to fenbuconazole (Fig. 1), but only 28 isolates were classified as DMI-R to propiconazole. By comparison, none of the DMI-S isolates had the 'Mona' genotype (Fig. 1), but 32 isolates classified as DMI-RS to propiconazole had the 'Mona' genotype.

Interestingly, isolates producing a 311-bp amplicon had a wide range of sensitivity phenotypes to both fenbuconazole and propi- 
conazole (Fig. 1). Specifically, \%RG values ranged from 0.0 to $47.6 \%$ (mean $\%$ RG of $10.31 \pm 0.5 \%$ ) on $0.3 \mu \mathrm{g} / \mathrm{ml}$ fenbuconazole, and ranged from 0.0 to $38.8 \%$ (mean $\%$ RG of $6.44 \pm 0.5$ ) on 0.9 $\mu \mathrm{g} / \mathrm{ml}$ propiconazole. While the majority of these isolates were DMI-S to fenbuconazole (196 of 353 isolates lacking 'Mona') and propiconazole (244 of 353 isolates lacking 'Mona'), 140 and 99 isolates were DMI-RS, and 18 and 10 isolates were DMI-R, respectively (Fig. 1). By comparison, all isolates that produced an 1,815-bp amplicon were DMI-RS to fenbuconazole, but DMI-S to propiconazole (Fig. 1).

Evaluation of DMI fungicides for control of brown rot on detached blossoms and fruit. In each of the four experiments investigating blossom blight and fruit rot development in response to protective and therapeutic applications of DMI fungicides, isolate phenotype (protective applications on blossoms $P=0.0003$; therapeutic applications on blossoms $P<0.0001$; protective applications on fruit $P<0.0001$; therapeutic applications on fruit $P=0.0022$ ), fungicide treatment (protective applications on blossoms $P<$ 0.0001 ; therapeutic applications on blossoms $P<0.0001$; protective applications on fruit $P<0.0001$; therapeutic applications on fruit $P=0.0005$ ), and the interaction of isolate phenotype and fungicide treatment (protective applications on blossoms $P=$ 0.0098 ; therapeutic applications on blossoms $P=0.0013$; protective applications on fruit $P<0.0001$; therapeutic applications on fruit $P=0.0075$ ) were significant. Due to the significant interaction between isolate phenotype and fungicide treatment, estimated adjusted means of main effects, as determined by the LSMEANS procedure of SAS, are presented separately for each isolate by fungicide treatment combination in each of the four experiments (Figs. 2 and 3). In all four experiments, inoculated water control treatments had a high level (>70\%) of blossom blight and brown fruit rot incidence (Figs. 2 and 3). By comparison, noninoculated water control treatments had no blossom blight or brown fruit rot, ruling out the possibility of background infections.

On detached cherry blossoms inoculated with any of the three isolates, protective applications of fenbuconazole resulted in consistently lower blossom blight incidence compared to water and propiconazole applications (Fig. 2A). For example, blossom blight incidence for blossoms inoculated with the DMI-R isolate was $78.8 \%$ following protective applications of propiconazole compared to $15.2 \%$ following protective applications of fenbuconazole (Fig. 2A). Protective applications of propiconazole to blossoms inoculated with the DMI-S and DMI-RS isolates, but not the DMI$\mathrm{R}$ isolate, had a significantly lower incidence of blossom blight than the water control (Fig. 2A). By comparison, therapeutic applications of fenbuconazole and propiconazole resulted in equivalent or higher incidences of blossom blight than those observed for corresponding protective treatments inoculated with the DMI-S and DMI-RS isolates (Fig. 2A and B). Against the DMI-R isolate, therapeutic applications of either fungicide resulted in a level of blossom blight incidence statistically equivalent to that of the water control (Fig. 2B).

Protective applications of fenbuconazole resulted in a consistently lower incidence of brown fruit rot compared to water and propiconazole applications to detached fruit inoculated with the DMI-S, DMI-RS, or DMI-R isolate (Fig. 3A). Protective applications of propiconazole to detached fruit appeared to be stimulatory to the DMI-R isolate given that the incidence of fruit rot $(98.0 \%)$ was higher than the incidence of fruit rot following an application of the water control (70.7\%) (Fig. 3A).

Therapeutic applications of fenbuconazole resulted in lower fruit rot incidence than the water control on fruit inoculated with the DMI-S isolate, but not the DMI-RS isolate (Fig. 3B). A therapeutic application of propiconazole resulted in slightly lower incidences of brown fruit rot than the water control for both the DMI-S and DMI-RS isolates (Fig. 3B). On fruit inoculated with the DMI-R isolate, the incidence of fruit rot was statistically equivalent among treatments involving therapeutic applications of fenbuconazole $(68.1 \%)$, propiconazole $(70.0 \%)$, or water $(72.0 \%)$ (Fig. 3B).

\section{Discussion}

Since 2005, we have observed, and producers in New York and Pennsylvania have reported, brown fruit rot control failures in stone fruit orchards following the use of DMI fungicides. In 2007, we first identified DMI resistance in New York along with the presence of 'Mona' (15). In the present study, we endeavored to conduct a more comprehensive investigation of the prevalence of 'Mona', DMI sensitivity, and the relationship between the in vitro sensitivity and 'Mona' for M. fructicola populations resulting from brown fruit rot control failures in New York and Pennsylvania stone fruit orchards from 2005 to 2009.

Sensitivity of $M$. fructicola populations to the DMI fungicides fenbuconazole and propiconazole. During the study, we identified and evaluated a baseline orchard (TLR) in the Finger Lakes region. Similar to baseline populations reported for $M$. fructicola and other pathogens $(12,25,26,34)$, the baseline orchard TLR was characterized by isolates highly sensitive $(<1 \%$ mean $\mathrm{RG})$ to both propiconazole and fenbuconazole with little variability within the population (population mean relative growth standard error $<1 \%$ ). Compared with historical data from New York M. fructicola baseline isolates in 1994 (31), TLR isolates had a slightly higher population mean relative growth, but responses of individual isolates were within the range of those from the 1994 baseline populations

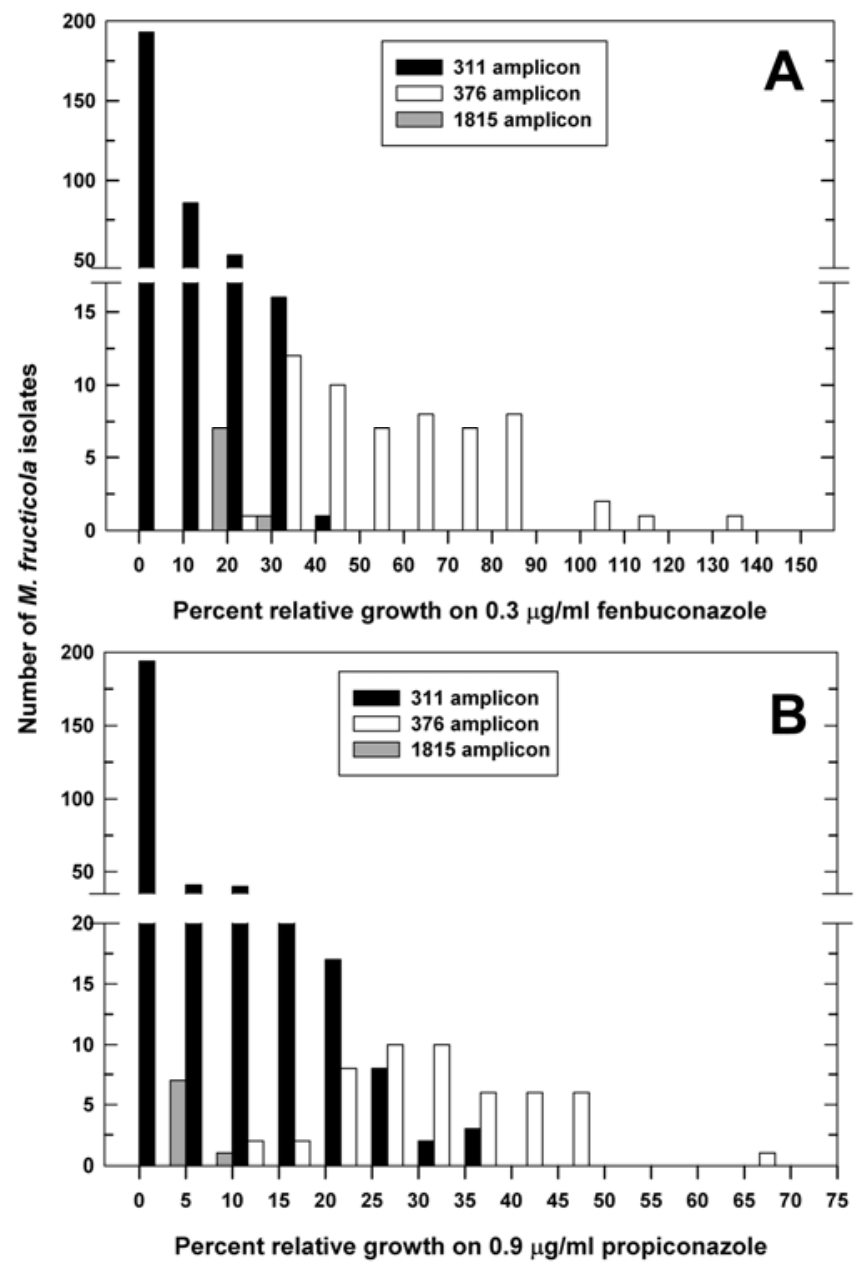

Fig. 1. Distribution of $\mathbf{A}$, fenbuconazole and $\mathbf{B}$, propiconazole percent relative growth (\%RG) values for different CYP51A1 upstream amplicon sizes for all 415 Monilinia fructicola isolates. Bars represent total number of isolates amplifying either a 311-bp amplicon lacking the 'Mona' determinant (black), a 376-bp amplicon containing the 'Mona' determinant (white), or a 1,815-bp amplicon lacking the 'Mona' determinant (gray), for bins representing \%RG ranges on potato dextrose agar amended with either $\mathbf{A}, 0.3 \mu \mathrm{g} / \mathrm{ml}$ fenbuconazole or $\mathbf{B}, 0.9 \mu \mathrm{g} / \mathrm{ml}$ propiconazole. White, gray, and black bars are differentially positioned within bins to allow visual discrimination, not to imply a specific subset of $\% R G$ values within a bin. 
(data not shown). Hence, the TLR population has likely remained baseline for the last 16 years and was likely unaffected by the ingress of M. fructicola isolates from DMI-exposed populations in the region.

In addition to the baseline site, we surveyed a total of 385 isolates from 16 commercial stone fruit operations in New York and one in Pennsylvania. Although all commercial populations had been collected during a season with a brown fruit rot epidemic following DMI applications, only three populations (RJO6, Beckens FF, and ChocMF) were composed primarily of resistant isolates possessing the 'Mona' genotype, and only six populations (HVC07, EO-07, New Royal, Bittner 108, MCTY, and Bittner 208) were primarily composed of isolates with either resistance or reduced sensitivity to fenbuconazole and propiconazole. The existence of $M$. fructicola populations with reduced sensitivity and resistance to DMI fungicides is not surprising given previously published reports from New York $(15,23)$ and from South Carolina (26,34), indicating diminished DMI efficacy within only 3 years of use or as few as 12 DMI applications (34). In contrast, eight populations (Bittner05, B. Palmer, JFNec08, JFCh09, LIWicomb, NYSAES, DB08, and HVL05) were composed primarily of DMI-S isolates despite the fact that fungicide application records for all of the commercial orchards surveyed indicated a minimum of 15 DMI applications. Within this group, however, mild brown fruit rot epidemics in orchards LIWicomb, NYSAES, DB08, MTCY, and HVL05 allowed the collection of only a small number of unique

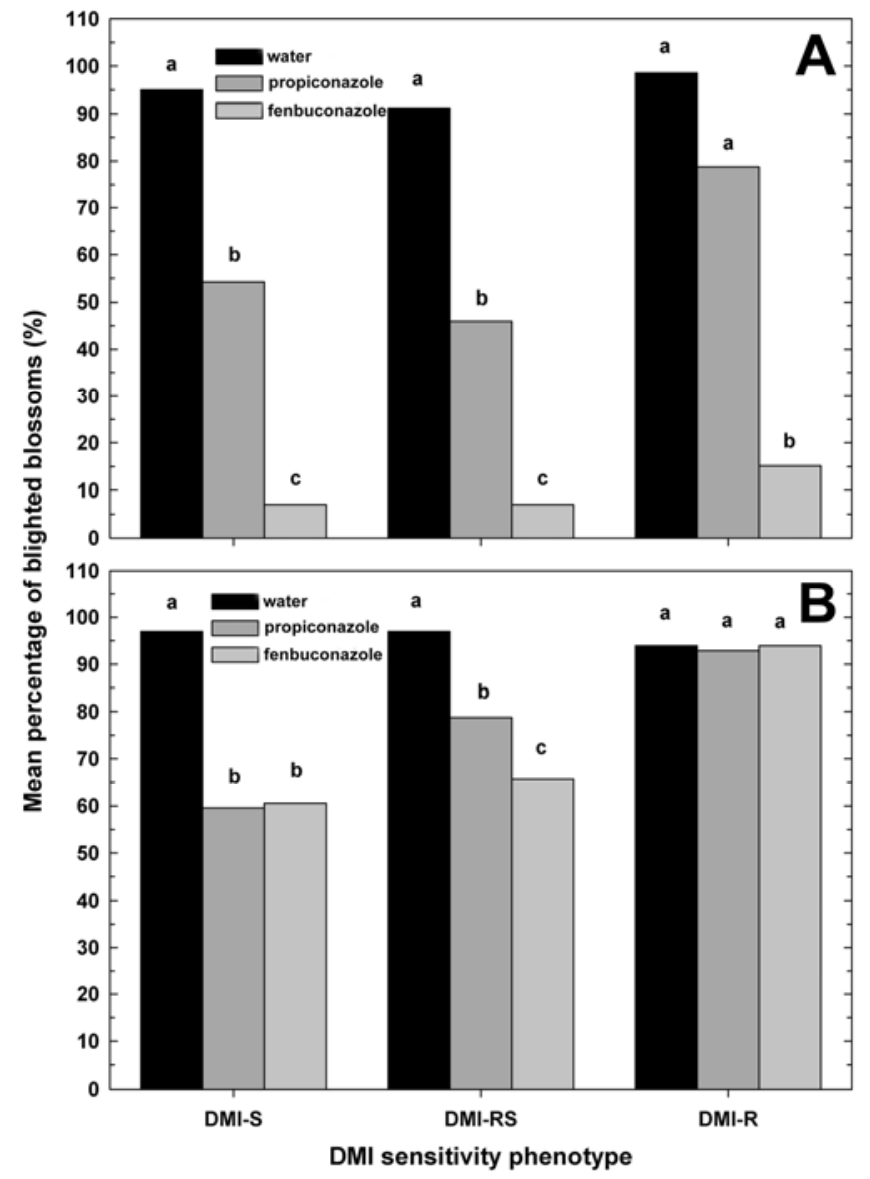

Fig. 2. Effect of $\mathbf{A}$, protective and $\mathbf{B}$, therapeutic applications of fenbuconazole (Indar 2F) and propiconazole (Orbit 3.6EC) on detached cherry blossoms inoculated with either a demethylation inhibitor sensitive (DMI-S), a DMI-reduced sensitive (DMI-RS), or a DMI-resistant (DMI-R) Monilinia fructicola isolate. Fungicides were applied either A, protectively $24 \mathrm{~h}$ prior to inoculation, or B, curatively $48 \mathrm{~h}$ following inoculation. Blossom blight incidence for fungicide treatments is depicted separately for each of the three isolate phenotypes (DMI-S, DMI-RS, and DMI-R). Each bar represents the adjusted estimated mean incidence. Bars denoted by the same letter indicate a lack of statistical significance $(\alpha=0.05)$ among adjusted estimated mean incidences for all treatment combinations. isolates, and we feel that this number is too small to make conclusions regarding population sensitivity. While many of the orchards' populations were composed primarily of DMI-S isolates, nearly all of the populations had some DMI-RS and/or DMI-R isolates and a wider range of sensitivities than the baseline location, which provides some indication of the impact of long-term DMI use in New York. For example, Bittner05 had DMI-RS isolates, and population responses ranged from 0.00 to $18.96 \%$ and 0.00 to $16.10 \% \mathrm{RG}$ on fenbuconazole and propiconazole amended medium, respectively, but the majority of isolates recovered had nearly baseline sensitivity levels $(<1 \% \mathrm{RG})$ to DMI fungicides. Certainly, wide ranges of isolate sensitivity exist within a population, and the development of isolates with DMI-RS phenotypes are characteristic of extended exposure to DMI fungicides as reported for other fungal pathogens of fruit crops including Venturia inaequalis (13), Blumeriella jaapii (24), and Monilinia oxycocci (19).

Only the three orchard populations primarily composed of DMI$\mathrm{R}$ isolates (RJO6, Beckens FF, and ChocMF) had recurring brown rot outbreaks in consecutive years during and following the survey (personal observation). By comparison, none of the other commercial orchards predominantly composed of DMI-S or DMI-RS isolates reported outbreaks in consecutive years despite continued DMI use (personal observation). DMI fungicides have been successfully used to manage orchard populations with reduced sensitivity in South Carolina for nearly 15 years (26). Thus, the lack of recurring outbreaks in these populations suggests that other factors

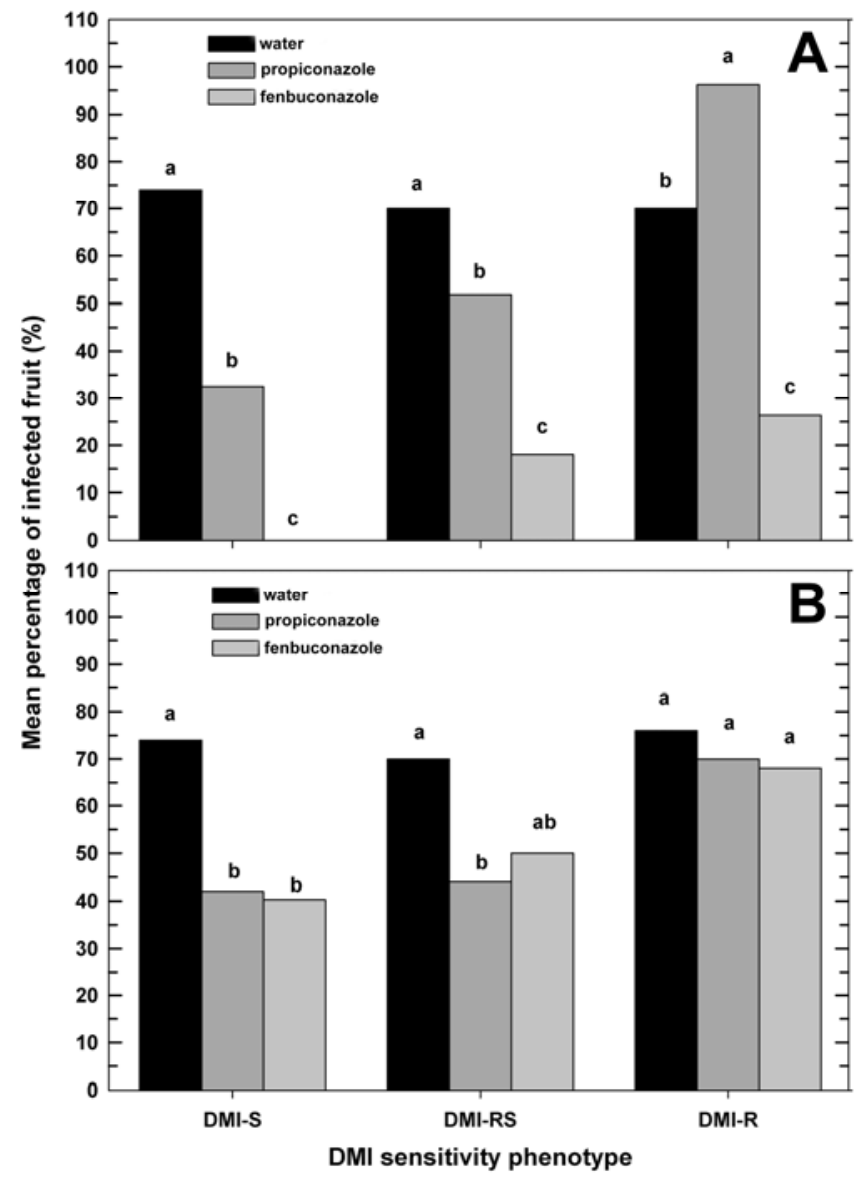

Fig. 3. Effect of $\mathbf{A}$, protective and $\mathbf{B}$, therapeutic applications of fenbuconazole (Indar 2F) and propiconazole (Orbit 3.6EC) on detached cherry fruit inoculated with either a demethylation inhibitor sensitive (DMI-S), a DMI-reduced sensitive (DMI$\mathrm{RS}$ ), or a DMI-resistant (DMI-R) Monilinia fructicola isolate. Fungicides were applied either A, protectively $24 \mathrm{~h}$ prior to inoculation or B, curatively $48 \mathrm{~h}$ following inoculation. Brown fruit rot incidence for fungicide treatments is depicted separately for each of the three isolate phenotypes (DMI-S, DMI-RS, and DMI-R). Each bar represents the adjusted estimated mean incidence. Bars denoted by the same letter indicate a lack of statistical significance $(\alpha=0.05)$ among adjusted estimated mean incidences for all treatment combinations. 
related to fungicide application (e.g., rate, coverage, or timing) or seasonal weather may have contributed to the DMI product failures against populations with reduced sensitivity. It is postulated (26) that hot humid weather favoring brown rot growth coincident with rain events may remove or effectively reduce rates of the fungicide prior to germination to the point where DMI-RS isolates may overcome the fungicide.

The prevalence of 'Mona' and in vitro sensitivity to the DMI fungicides fenbuconazole and propiconazole. Across the entire collection of isolates, there was considerable variation in DMI sensitivity. This type of response is consistent with the theory that DMI fungicide resistance is multigene or quantitative in nature $(4,13,20)$. While previous studies have classified nearly all $M$. fructicola isolates with the 'Mona' genotype as DMI-R $(1,15)$, we found that the 'Mona' genotype can be associated with isolates having higher levels of sensitivity, especially to propiconazole. Hence, the presence of 'Mona' did not necessarily indicate that an isolate would display a DMI-R phenotype by our classification standards when tested in vitro. At the same time, we found isolates with a DMI-R phenotype that lacked the 'Mona' determinant. Hence, 'Mona' likely contributes to a loss of sensitivity to DMIs as previously demonstrated $(15,16)$, but this is likely only a portion of the quantitative resistance response. Considering the spectrum of sensitivities we observed with both DMI fungicides and the loose relationship between 'Mona' genotype and isolate sensitivity, we feel that in vitro evaluation of DMI sensitivity is still essential for M. fructicola.

In addition to wide ranges in sensitivity responses, we observed differences between fenbuconazole and propiconazole in the level of inhibition afforded to individual isolates and populations at their respective discriminatory doses. Although \%RG values of individual isolates for fenbuconazole were slightly higher than those for propiconazole, isolates were exposed to three times as much propiconazole. Previously, 16 New York isolates from two commercial orchards, RJ06 and TLR, were tested for sensitivity to propiconazole at a discriminatory dose of $0.3 \mu \mathrm{g} / \mathrm{ml}$ (15). While the dose chosen by Luo et. al. (15) would have allowed direct comparison of the two fungicides on unit of active ingredient (a.i.) basis, that dose was chosen based on a collection of South Carolina baseline isolates (2) as opposed to those from New York (31). Nevertheless, the 16 RJ06 and TLR isolates tested previously at $0.3 \mu \mathrm{g} / \mathrm{ml}$ propiconazole (15) still had higher relative growth values than those tested at $0.3 \mu \mathrm{g} / \mathrm{ml}$ fenbuconazole in the current study (data not shown). Hence, it is likely that fenbuconazole is simply intrinsically more active in vitro against $M$. fructicola from New York.

Evaluation of DMI fungicides for control of brown rot on detached blossoms and fruit. Given the prevalence of DMI resistance and 'Mona' in M. fructicola populations throughout the eastern United States $(1,9,15)$, a better understanding of the field implications of DMI-R isolates with the 'Mona' genotype is needed. In this study, we also investigated the potential of two DMI fungicides to prevent infection of flowers and fruit when challenged with representative $M$. fructicola isolates of different phenotypes and genotypes. Although the M. fructicola isolates from the current study had a wide range of $\%$ RG values to the two DMI fungicides, the choice of isolates with \% RG values in the highest range of each phenotype class ensured the most rigorous challenge to fungicide efficacy. Given the choice of representative isolates, it is likely that isolates with lower \% RG values should provide comparable or lower incidences when treated with the two fungicides.

When applied protectively to blossoms and fruit inoculated with any of the isolates (DMI-S, DMI-RS, or DMI-R), fenbuconazole (Indar 2F) applications resulted in significantly lower brown rot incidence than those of propiconazole (Orbit 3.6EC). Fenbuconazole was applied at a higher rate (see Materials and Methods), but propiconazole (Orbit 3.6EC, $41.8 \%$ a.i.) has more than $1.75 \times$ the a.i. of fenbuconazole (Indar 2F, 23.5\% a.i.) in formulation. This performance difference could be attributed to fundamental differences in biochemistry that make fenbuconazole a better protectant $(5,29)$ or further support a higher intrinsic activity for fenbuconazole. In therapeutic application experiments, there were no significant differences between propiconazole and fenbuconazole performance with the exception of fenbuconazole applications to detached blossoms inoculated with the DMI-RS isolate. We had anticipated propiconazole to demonstrate greater therapeutic efficacy for all phenotypes given that it is considered to be a more potent postinfection fungicide than fenbuconazole due to differences in water solubility and other fundamental biochemical properties $(5,29)$. In the current study, the improved curative activity of propiconazole was likely balanced by the differences in intrinsic activity between the two DMIs. Indeed, differences in triazole performance both in planta and in vitro to control for M. fructicola (8) and other pathogens such as $U$. necator $(6,33)$ and $V$. inaequalis (12) have been documented. In all of the orchards surveyed in the current study, fenbuconazole was the primary DMI fungicide applied for brown rot control, which indicated that $M$. fructicola populations in New York may have become less sensitive specifically to fenbuconazole. However, the fact that higher \%RG values were observed for fenbuconazole compared to propiconazole in all orchard populations including the sensitive and baseline suggests that fungicidespecific adaptation may not exist in this system.

Irrespective of the differences in fungicide performance, therapeutic applications of either DMI fungicide failed to reduce brown rot incidence on blossoms or fruit inoculated with the DMI-R isolate. Our results are in agreement with a previous study (8), indicating that protective applications of DMI fungicides were also more effective at reducing brown fruit rot incidence than therapeutic applications. The authors only performed experiments on detached peach fruit, and used a 24-h postinoculation timing. By comparison, we had nearly identical rates and made therapeutic applications $48 \mathrm{~h}$ after infection to cherry blossoms and fruit. Overall, the levels of brown rot incidence were comparable between the two studies, but unlike the previous work (8), we observed differences in the level of brown rot incidence resulting from infection by DMI-RS and DMI-R isolates. Had we evaluated therapeutic application only $24 \mathrm{~h}$ postinoculation, we too may not have been able to resolve differences between DMI-RS and DMI-R isolates.

The high degree of target specificity and the dual modes of activity (protective and curative) make DMI fungicides an attractive choice for the control of brown rot in stone fruit operations in New York. With the emergence of M. laxa in New York, DMI use during bloom for blossom blight control may become more prevalent (30). We have shown that while the presence of 'Mona' appears to be an indicator for reduced sensitivity to DMI fungicides, it is likely only one of many factors involved in acquired quantitative resistance to this class of fungicides. While the rapid detection of 'Mona' in the absence of in vitro testing would certainly be of value for the identification of "at-risk" stone fruit operations, low population frequencies of 'Mona' may have little bearing on the overall population sensitivity. Further, the presence of 'Mona' and in vitro resistance may not necessitate ceasing DMI fungicide use. We have demonstrated that fenbuconazole formulated as Indar $2 \mathrm{~F}$ can theoretically provide considerable protection against infection by a DMI-RS isolate or a DMI-R isolate containing 'Mona'. Hence, the use of DMI fungicides will continue to be an important component in stone fruit and brown rot management programs in New York.

\section{Acknowledgments}

This study was supported by state, federal, and institutional funds appropriated to the New York State Agricultural Experiment Station, Cornell University. This study is part of CSREES project NYG-625420 (Accession: 021118). We also thank Henry Ngugi, David Rosenberger, and Deborah Breth for their assistance with the identification of brown fruit rot control failures and collection of M. fructicola isolates.

\section{Literature Cited}

1. Burnett, A., Lalancette, N., and McFarland, K. 2010. First report of the peach brown rot fungus Monilinia fructicola resistant to demethylation in- 
hibitor fungicides in New Jersey. Plant Dis. 94:126.

2. Cox, K. D., Bryson, P. K., and Schnabel, G. 2007. Instability of propiconazole resistance and fitness in Monilinia fructicola. Phytopathology 97:448453.

3. Cox, K. D., Quello, K., Deford, R. J., and Beckerman, J. L. 2009. A rapid method to quantify fungicide sensitivity in the brown rot pathogen Monilinia fructicola. Plant Dis. 93:328-331.

4. De Waard, M. A., Georgopoulos, S. G., Hollomon, D. W., Ishii, H., Leroux, P., Ragsdale, N. N., and Schwinn, F. J. 1993. Chemical control of plant diseases: Problems and prospects. Annu. Rev. Phytopathol. 31:403-421.

5. Ehr, R. J., Kemmitt, G. M., and Ouimette, D. 2008. Periodic table of the fungicides 3.0. Dow AgroSciences, Indianapolis, IN. LO1-818-020, BOD 010-30143.

6. Erickson, E. O., and Wilcox, W. F. 1997. Distributions of sensitivities to three sterol demethylation inhibitor fungicides among populations of $U n$ cinula necator sensitive and resistant to triadimefon. Phytopathology 87:784-791.

7. Fulton, C. E., and Brown, A. E. 1997. Use of SSU rDNA group-I intron to distinguish Monilinia fructicola from M. laxa and M. fructigena. FEMS Microbiol. Lett. 157:307-312.

8. Holb, I. J., and Schnabel, G. 2007. Differential effect of triazoles on mycelial growth and disease measurements of Monilinia fructicola isolates with reduced sensitivity to DMI fungicides. Crop Prot. 26:753-759.

9. Janisiewicz, W. J., Biggs, A. R., Jurick, W. M., II, Vico, I., and Conway, W. S. 2010. Characteristics of Monilinia fructicola isolates from decayed stone fruits in eastern West Virginia. (Abstr.) Phytopathology 100:S56.

10. Jones, A. L., and Ehret, G. R. 1976. Isolation and characterization of benomyl-tolerant strains of Monilinia fructicola. Plant Dis. Rep. 60:765-769.

11. Köller, W. 1999. Chemical approaches to managing plant pathogens. Pages 337-376 in: Handbook of Pest Management. J. R. Ruberson, ed. Marcel Dekker, New York.

12. Köller, W. D., Parker, D. M., and Reynolds, K. L. 1991. Baseline sensitivities of Venturia inaequalis to sterol demethylation inhibitors. Plant Dis. 75:726-728.

13. Köller, W. D., Wilcox, W. F., Barnard, J., Jones, A. L., and Braun, P. G. 1997. Detection and quantification of resistance of Venturia inaequalis populations to sterol demethylation inhibitors. Phytopathology 87:184-190.

14. Köller, W. D., and Wubben, J. P. 1989. Variable resistance factors of fungicides acting as sterol demethylation inhibitors. Pestic. Sci. 26:133-145.

15. Luo, C.-X., Cox, K. D., Amiri, A., and Schnabel, G. 2008. Occurrence and detection of the DMI resistance-associated genetic element 'Mona' in Monilinia fructicola. Plant Dis. 92:1099-1103.

16. Luo, C. X., and Schnabel, G. 2008. The cytochrome P450 lanosterol $14 \alpha-$ demethylase gene is a demethylation inhibitor fungicide resistance determinant in Monilinia fructicola field isolates from Georgia. Appl. Environ. Microbiol. 74:359-366.

17. Ma, Z., Yoshimura, M. A., Holtz, B. A., and Michailides, T. J. 2004. Characterization and PCR-based detection of benzimidazole-resistant isolates of Monilinia laxa in California. Pest Manag. Sci. 61:449-457.

18. Ma, Z., Yoshimura, M. A., and Michailides, T. J. 2003. Identification and characterization of benzimidazole resistance in Monilinia fructicola from stone fruit orchards in California. Appl. Environ. Microbiol. 69:7145-7152.

19. McManus, P. S., Best, V. M., Voland, R. P., and Leininger, B. L. 1999. Sen- sitivity of Monilinia oxycocci to fenbuconazole and propiconazole in vitro and control of cranberry cottonball in the field. Plant Dis. 83:445-450.

20. Miller, G. L., Stevenson, K. L., and Burpee, L. L. 2002. Sensitivity of Sclerotinia homoeocarpa isolates to propiconazole and impact on control of dollar spot. Plant Dis. 86:1240-1246.

21. Nakaune, R., Adachi, K., Nawata, O., Tomiyama, M., Akutsu, K., and Hibi, T. 1998. A novel ATP-binding cassette transporter involved in multidrug resistance in the phytopathogenic fungus Penicilium digitatum. Appl. Environ. Microbiol. 64:3983-3988.

22. Ogawa, J. M., and English, H. 1995. Brown rot. Pages 7-10 in: Compendium of Stone Fruit Diseases. J. M. Ogawa, E. I. Zehr, G. W. Bird, D. F. Ritchie, K. Uriu, and J. K. Uyemoto, eds. American Phytopathological Society, St. Paul, MN

23. Parker, D. M., Zhang, N., Smart, C. D., and Köller, W. 2006. Polymorphism of 14-alpha demythylase gene (CYP51) in brown rot pathogen Monilinia fructicola from a resistant orchard in New York State. (Abstr.) Phytopathology 96:S90.

24. Proffer, T. J., Berardi, R., Ma, Z., Nugent, J. E., Ehret, G. R., McManus, P. S., Jones, A. L., and Sundin, G. W. 2006. Occurrence, distribution, and polymerase chain reaction-based detection of resistance to sterol demethylation inhibitor fungicides in populations of Blumeriella jaapii in Michigan. Phytopathology 96:709-717.

25. Reynolds, K. L., Brenneman, T. B., and Bertrand, P. F. 1997. Sensitivity of Cladosporium caryigenum to propiconazole and fenbuconazole. Plant Dis. 81:163-166.

26. Schnabel, G., Bryson, P. K., Bridges, W. C., and Brannen, P. 2004. Reduced sensitivity in Monilinia fructicola to propiconazole in Georgia and implications for disease management. Plant Dis. 88:1000-1004.

27. Schnabel, G., and Dai, Q. 2004. Heterologous expression of the P450 sterol $14 \alpha$-demethylase gene from Monilinia fructicola reduces sensitivity to some but not all DMI fungicides. Pest. Biochem. Physiol. 78:31-38.

28. Sonoda, R. M., and Ogawa, J. M. 1982. Growth rate of Monilinia fructicola resistant and sensitive to benomyl on potato dextrose agar and on peach fruit. Plant Dis. 66:1155-1156.

29. Thomson, W. T. 2000. Agricultural Chemicals: Book IV Fungicides. Thomson Publications, Fresno, CA.

30. Villani, S. M., and Cox, K. D. 2010. Confirmation of European brown rot caused by Monilinia laxa on tart cherry, Prunus cerasus, in western New York. Plant Dis. 94:783.

31. Wilcox, W. F., and Burr, J. A. 1994. Baseline sensitivity of Monilinia fructicola to six DMI fungicides. Phytopathology 84:1078.

32. Yoshimura, M. A., Luo, Y., Ma, Z., and Michailides, T. J. 2004. Sensitivity of Monilinia fructicola from stone fruit to thiophanate-methyl, iprodione, and tebuconazole. Plant Dis. 88:373-378.

33. Ypema, H. L., Ypema, M., and Gubler, W. D. 1997. Sensitivity of Uncinula necator to benomyl, triadimefon, myclobutanil, and fenarimol in California. Plant Dis. 81:293-297.

34. Zehr, E., Luszcz, L. A., Olien, W. C., Newall, W. C., and Toler, J. E. 1999. Reduced sensitivity in Monilinia fructicola to propiconazole following prolonged exposure in peach orchards. Plant Dis. 83:913-916.

35. Zehr, E. I., Toler, J. E., and Luszcz, L. A. 1991. Spread and persistence of benomyl-resistant Monilinia fructicola in South Carolina peach orchards. Plant Dis. 75:590-593. 